Article

\title{
Synthesis and Evaluation of New Potential Benzo[a]phenoxazinium Photosensitizers for Anticancer Photodynamic Therapy
}

\author{
Juan Zhang ${ }^{1,2}$, Wellington Tavares de Sousa Júnior ${ }^{2}$, Victor Carlos Mello da Silva ${ }^{2}$, \\ Mosar Correa Rodrigues ${ }^{2,3}$, José Athayde Vasconcelos Morais 2,3 (iD), Jia-Li Song ${ }^{1}$, \\ Zhi-Qiang Cheng ${ }^{1}$, João Paulo Figueiró Longo ${ }^{3}$ (D) , Ricardo Bentes Azevedo ${ }^{3}$, \\ Cheng-Shi Jiang ${ }^{1, * \mathbb{B}}$, Luís Alexandre Muehlmann ${ }^{2, *}$ and Hua Zhang ${ }^{1, *}$ \\ 1 School of Biological Science and Technology, University of Jinan, Jinan 250022, China; \\ zjandzq@163.com (J.Z.); 13285419800@163.com (J.-L.S.); czq13515312897@163.com (Z.-Q.C.) \\ 2 Faculty of Ceilandia, University of Brasília, Brasilia 72220275, Brazil; \\ wellingtonjunior123@hotmail.com (W.T.d.S.J.); victooormellooo@gmail.com (V.C.M.d.S.); \\ mosarcr@gmail.com (M.C.R.); joseathayde_9@hotmail.com (J.A.V.M.); \\ 3 Institute of Biological Sciences, University of Brasília, Brasilia 70910900, Brazil; \\ jplongo82@gmail.com (J.P.F.L.); razevedo@unb.br (R.B.A.) \\ * Correspondence: jiangchengshi-20@163.com (C.-S.J.); luismuehlmann88@gmail.com (L.A.M.); \\ bio_zhangh@ujn.edu.cn (H.Z.); Tel.: +86-0531-8973-6199 (H.Z.)
}

Received: 16 May 2018; Accepted: 8 June 2018; Published: 13 June 2018

\begin{abstract}
The use of photodynamic therapy (PDT) and development of novel photosensitizers (PSs) for cancer treatment have received more and more attention nowadays. In the present work, five benzo[ $[a]$ phenoxazinium derivatives have been prepared and evaluated for their in vitro anticancer photodynamic activity for the first time. They are red light absorbers and show low fluorescence quantum yield. Of these compounds, PS4 exhibited a higher quantum yield for reactive oxygen species (ROS) generation. The assays with cells in vitro showed that PS1 and PS4 were not significantly toxic in the dark, but was robustly toxic against the murine breast adenocarcinoma cells 4T1 and normal murine fibroblast cells NIH-3T3 upon photoactivation. More interestingly, PS5 was particularly selective towards 4T1 cancer cells and nearly non-phototoxic to non-cancerous NIH-3T3 cells. The results described in this report suggest that these new benzo[ $a]$ phenoxazinium derivatives are potential candidates as PSs for anticancer PDT. Further investigation of benzo[ $a]$ phenoxaziniums for anticancer PDT is warranted.
\end{abstract}

Keywords: benzo[a]phenoxazinium; photosensitizer; reactive oxygen species; photodynamic therapy; anticancer

\section{Introduction}

Photodynamic therapy (PDT) is a minimally invasive protocol that has been used in anticancer therapy for a long time [1]. PDT is based on the focal photoactivation of photosensitizers (PSs), which can directly act on the target tissues and then elicit photochemical reactions that eventually lead to oxidative stress [2]. The main consequences of these events include direct cytotoxicity, collapse of the tumor microvasculature, and/or activation of immune response against tumor antigens [3]. A particularly important benefit of PDT as a cancer therapy is the possibility to restrict its effects to the irradiated site, sparing the normal tissues. Although PDT has been successfully applied in the treatment of skin, gynecological, gastrointestinal, and some head and neck cancers for a long time, only a few PSs (e.g., porfimer sodium, temoporfin, aminolevulinic acid and photofrin) have been put 
into the market $[4,5]$. Up to now, most current work focuses on the improvement of porphyrin and chlorin-type PS molecules and, especially, synthesis of new type of PSs with high water solubility, strong absorption in near-infrared region, and long half-life $[2,6]$.

During our continuing project for developing new generation of PSs [7-10], the benzo[a]phenoxazinium chlorides dyes came to our attention due to their good photostability, high molar absorption, long-wavelength absorption, and relative low fluorescence quantum yield [11-13]. Literature survey indicated that benzo[a]phenoxazinium derivatives exhibited antifungal $[12,14]$, and antimalarial activity [15], and especially functioned as PSs in antimicrobial PDT [15-18]. However, to our knowledge, the potential anticancer PDT of benzo[a]phenoxazinium dyes has been little investigated [19]. In this context, the main objective of the present work was to design and synthesize several new benzo[a]phenoxazinium chlorides PS1-PS5 (Figure 1) and investigate their potential anticancer photodynamic activity.<smiles>CCN(CC)c1cc2c(cc1Cl)Oc1cc(NCCC(=O)OC)c3ccccc3c1N2</smiles><smiles>CCN(CC)c1ccccc1-c1ccccc1</smiles><smiles>CCN(CC)c1ccc2nc3c(cc2n1)oc1cc(NCCC(=O)NCCNC(=O)CCCCC2SC[C@H]4NC(=O)N[C@@H]24)c2ccccc2c13</smiles>

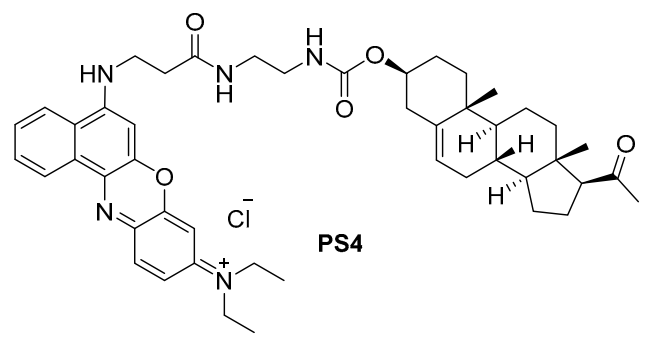<smiles>CCN(CC)c1ccc(-n2c3ccccc3c3cc(N(CC)CC)c(NCCC(=O)NCCNC(=O)CCNc4cc5oc6cc(N(CC)CC)ccc6c5c5ccccc45)cc32)c(Cl)c1</smiles>

Figure 1. Structures of benzo[a]phenoxazinium chlorides PS1-PS5.

\section{Results and Discussion}

\subsection{Design and Synthesis}

The ligand-mediated targeting (LMT) strategy in PDT has been explored to increase the efficacy and reduce adverse effects of PSs [2]. In the present study, five benzo[a]phenoxazinium chlorides possessing different functional fragments at the 5 -amino position were designed and prepared based on the LMT strategy. PS1 was a simple known benzo[a]phenoxazinium derivative with methyl propionate reported by Frade et al. $[13,14,20]$, which was shown to have antimicrobial activity against Saccharomyces cerevisiae [14], but its anticancer PDT had not yet been investigated. Other compounds are new synthetic benzo[a]phenoxazinium derivatives: PS2 possesses a morpholinoethylamine moiety, which is a well-known ligand for targeting lysosome [21]; PS3 is equipped with a biotin moiety, which is a well-known tumor-targeting molecule [22] and has been used for selective delivery of PS to cancer tissues [23,24]; PS4 was a conjugate of benzo[a]phenoxazinium and pregnenolone. Pregnenolone, known as a precursor to most hormones, had been explored as carrier of anticancer drugs [25]. In addition, several types of pregnenolone derivatives were reported to have anticancer activity by our and other groups [26-28]. PS5 was synthesized as the first benzo[a]phenoxazinium dimer to determine the superimposed effect of the benzo[ $a]$ phenoxazinium core on anticancer PDT efficacy.

The synthetic routes for target compounds PS1 to PS5 are depicted in Schemes 1-5, respectively. Briefly, compound 2 was synthesized by alkylation of 1-naphthylamine (1) with 3-bromopropanoic acid, 
and nitroso derivative 4 was prepared from the nitration reaction of 3-(diethylamino)phenol (3). Then a cyclization reaction of $\mathbf{2}$ and $\mathbf{4}$ (in refluxing methanol) produced target compound PS1. The coupling reaction of 2 with 2-morpholinoethanamine, tert-butyl (2-aminoethyl)carbamate, and pregnenolone derivative 8 yielded intermediates 5, 6 and 9, respectively. Deprotection of N-Boc in $\mathbf{6}$ followed by coupling with Biotin-NHS gave compound 7 or followed by reaction with 2 produced 10. Starting from intermediates 5, 7, 9, 10 and using compound 4 once again, the target benzo[a]phenoxaziniums PS2 to PS5 were finally obtained in the last step using a similar synthetic protocol as that of PS1. The ${ }^{1} \mathrm{H}$-, ${ }^{13}$ C-NMR, LR-MS and HR-MS spectra for PS1-PS5 can be found in Supplementary materials.
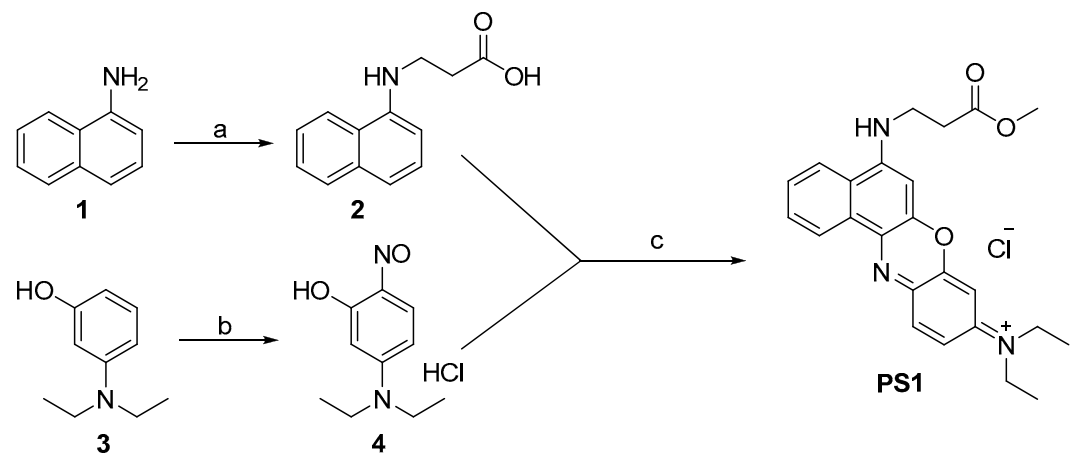

Scheme 1. The synthesis of PS1. Reagents and conditions: (a) 3-bromopropanoic acid, $\mathrm{Et}_{3} \mathrm{~N}, \mathrm{MeOH}$, reflux, overnight; (b) Cocn. $\mathrm{HCl}$, sodium nitrite, $\mathrm{H}_{2} \mathrm{O}, 0-5{ }^{\circ} \mathrm{C}, 3.5 \mathrm{~h}$; (c) Cocn. $\mathrm{HCl}, \mathrm{MeOH}$, reflux, $4 \mathrm{~h}$.<smiles>CCN(CC)c1ccc2c(c1)oc1cc(NCCC(=O)NCCN3CCOCC3)c(NCCN3CCOCC3)cc12</smiles>

Scheme 2. The synthesis of PS2. Reagents and conditions: (a) 2-morpholinoethanamine, HATU, iPrNEt ${ }_{2}$, $\mathrm{CH}_{2} \mathrm{Cl}_{2} ;$ (b) 4, cocn. $\mathrm{HCl}, \mathrm{EtOH}$, reflux, 4 h.<smiles>Cc1ccc2cccc(NCCC(=O)NCCNC(=O)CCCC[C@@H]3SC[C@H]4NC(=O)N[C@@H]43)c2c1</smiles><smiles></smiles>

Scheme 3. The synthesis of PS3. Reagents and conditions: (a) tert-butyl (2-aminoethyl)carbamate, HATU, iPrNEt ${ }_{2}, \mathrm{CH}_{2} \mathrm{Cl}_{2}$; (b) i. trifluoroacetic acid, $\mathrm{CH}_{2} \mathrm{Cl}_{2}, 0{ }^{\circ} \mathrm{C}$, overnight; ii. Biotin-NHS, $\mathrm{Et}_{3} \mathrm{~N}, \mathrm{CH}_{3} \mathrm{CN}$, r.t., overnight; (c) 4, EtOH, 5 drops of cocn. $\mathrm{HCl}$, reflux, $4 \mathrm{~h}$. 


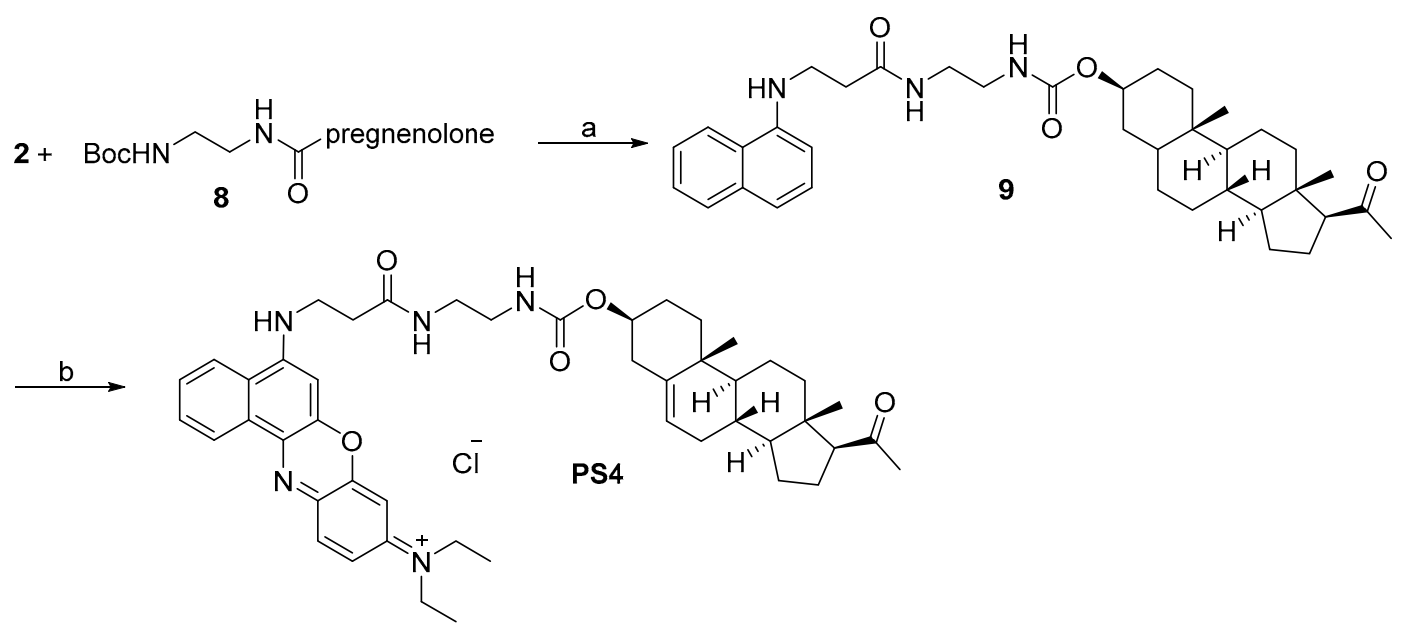

Scheme 4. The synthesis of PS4. Reagents and conditions: (a) i. trifluoroacetic acid, $\mathrm{CH}_{2} \mathrm{Cl}_{2}, 0{ }^{\circ} \mathrm{C}$, overnight; ii. 2, HATU, iPrNEt $2, \mathrm{CH}_{2} \mathrm{Cl}_{2}$, overnight.

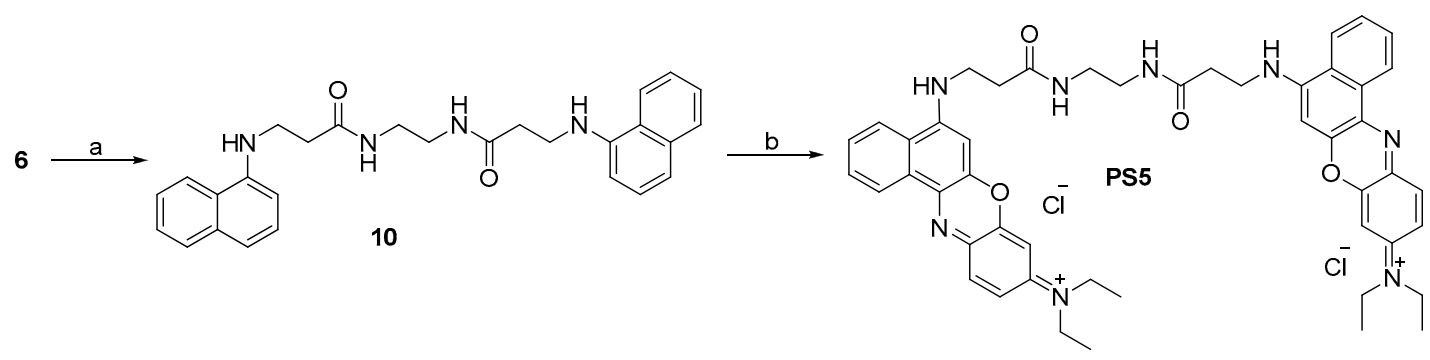

Scheme 5. The synthesis of PS5. Reagents and conditions: (a) i. trifluoroacetic acid, $\mathrm{CH}_{2} \mathrm{Cl}_{2}, 0{ }^{\circ} \mathrm{C}$, overnight; ii 2, HATU, iPrNEt $2, \mathrm{CH}_{2} \mathrm{Cl}_{2}$, overnight; (b) 4, EtOH, 5 drops of cocn. $\mathrm{HCl}$, reflux, $4 \mathrm{~h}$.

\subsection{Absorption and Emission Studies}

UV-vis absorption and emission spectra of $5 \mu \mathrm{M}$ PS1 to PS5 in water were measured to investigate their optical properties (Table 1 and Figure 2A). The absorption maxima $\left(\lambda_{\max }\right)$ for compounds PS1 to PS4 located at about $650 \mathrm{~nm}$ with the molar extinction coefficients $(\varepsilon)$ between 22,600 and $51,800 \mathrm{M}^{-1} \mathrm{~cm}^{-1}$, which can be ascribed to the $\pi-\pi^{*}$ transition of the large $\pi$ system of the benzo[a]phenoxazinium core. PS5 showed a shoulder peak at $649 \mathrm{~nm}\left(\varepsilon=35,600 \mathrm{M}^{-1} \mathrm{~cm}^{-1}\right)$ from the benzo $[a]$ phenoxazinium fluorophore. Meanwhile, PS5 also showed a main absorption at $604 \mathrm{~nm}$ with a higher $\varepsilon$ of $65,000 \mathrm{M}^{-1} \mathrm{~cm}^{-1}$, which probably resulted from the $\pi-\pi$ interaction of the two intramolecular benzo[ $a]$ phenoxazinium fluorophores as a result of the flexibility of the amide linker [29].

Table 1. Absorption and emission data of benzo[a]phenoxazinium chlorides PS1-PS5 in water.

\begin{tabular}{cccccc}
\hline Compound & $\boldsymbol{\lambda}_{\mathbf{a b s}}{ }^{\mathbf{a}}$ & $\mathbf{E}^{\mathbf{b}}$ & $\boldsymbol{\lambda}_{\mathbf{e m}}{ }^{\mathbf{a}}$ & $\Delta \boldsymbol{\lambda}^{\mathbf{a}}$ & $\boldsymbol{\varphi}$ \\
\hline PS1 & 648 & 47,400 & 681 & 33 & 0.075 \\
PS2 & 649 & 35,400 & 682 & 33 & 0.077 \\
PS3 & 650 & 51,800 & 684 & 34 & 0.082 \\
PS4 & 651 & 22,600 & 686 & 35 & 0.116 \\
PS5 & $649(604)$ & 35,600 & 686 & 37 & 0.025 \\
\hline \multicolumn{7}{c}{$(65,000)$} & ${ }^{\mathrm{a}} \mathrm{nm}^{\mathrm{b}} \mathrm{M}^{-1} \mathrm{~cm}^{-1}$.
\end{tabular}



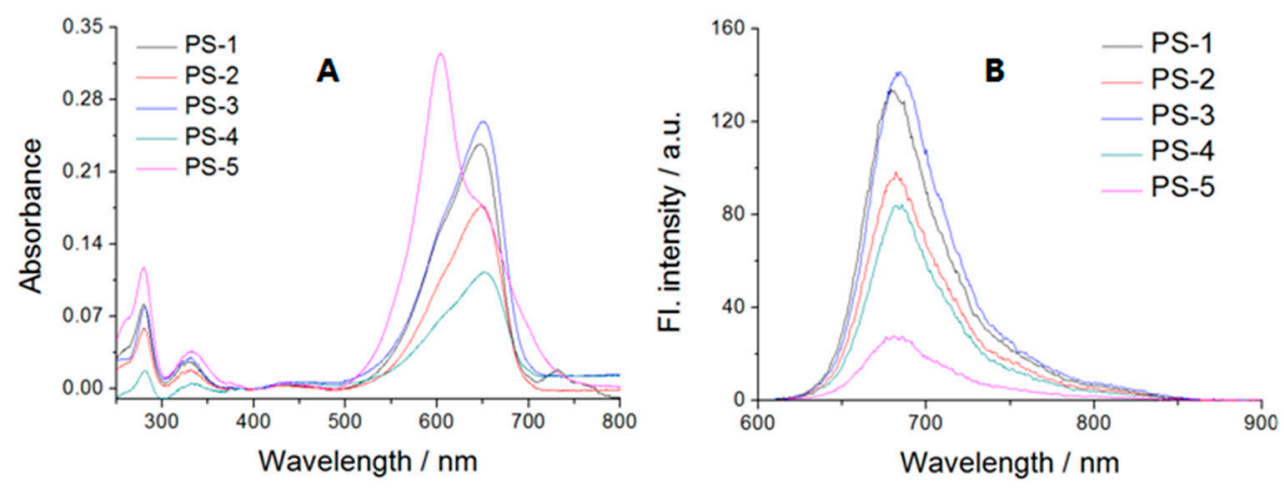

Figure 2. Absorption (A) and fluorescence ((B), excitation at $\lambda 600 \mathrm{~nm})$ spectra of PS1-PS5 at $5 \mu \mathrm{M}$ in water.

Under excitation at $600 \mathrm{~nm}$, all these compounds exhibited near-infrared emissions at about $681 \mathrm{~nm}$, with Stokes shifts of about $35 \mathrm{~nm}$ (Figure 2B). In addition, the relative fluorescence quantum yields $(\varphi)$ were measured in water using fluorescein as a standard $\left(\varphi_{\mathrm{S}}=0.98\right)$ [30]. These compounds all showed relatively low fluorescence quantum yields $(0.025$ to 0.116$)$, which is consistent with the result of previously reported benzo[ $a$ ]phenoxazinium chlorides [13]. This result indicates that PS1-PS5 may not tend to decay back to the ground state by emitting fluorescence after excitation and have a great potential in undergoing intersystem crossing to form a relatively long-lived triplet state, which is necessary for acting as desirable PDT candidates.

\subsection{ROS Production}

The reactive oxygen species (ROS) generated in photoreactions are the key factor for PDT as they can induce cytotoxicity via damage to different biomolecules, including proteins, nucleic acids and lipids [31,32]. Therefore, compounds PS1 to PS5 were evaluated for their effects on the production of ROS by DPBF method [7]. Figure 3 shows the results of ROS production when the compounds were irradiated with different energy densities. All these molecules produced ROS in an energy-dependent fashion, indicating that they are potential candidates for anticancer PDT. Remarkably, the photoactivated production of ROS was most intense with PS4, suggesting that this compound has the highest quantum yield for ROS generation. PS3, on the contrary, showed the lowest production of ROS compared with others.

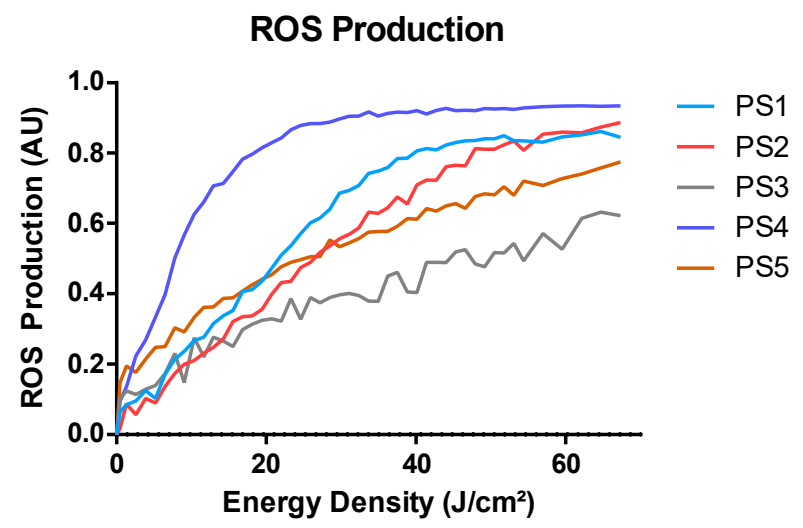

Figure 3. Photoactivated production of ROS by the candidate photosensitizers (PS1 to PS5, $40 \mu \mathrm{M}$ in water) expressed as arbitrary units (AU). 


\subsection{Photodynamic Activity Against Cells In Vitro}

Finally, in vitro photodynamic activities of PS1 to PS5 against two cell lines, including murine breast adenocarcinoma cell 4T1 and normal murine fibroblast cell NIH-3T3, were tested by irradiated (PDT) with $25.8 \mathrm{~J} / \mathrm{cm}^{2}$ of light $(\lambda 660 \mathrm{~nm}$ ) or not (dark) by MTT bioassay [33]. As shown in Figure 4, all the tested compounds did not display significant toxicity towards both NIH-3T3 and 4T1 cells in the dark with inhibition ratio less than $50 \%$ within the concentration range of 2.5 to $40 \mu \mathrm{M}$. The absence of toxicity in the dark is a requirement for a desirable PS, as it avoids that non-irradiated tissues become affected during a PDT protocol. Regarding the photodynamic activity, it is remarkable that both PS1 and PS4 were robustly phototoxic against 4T1 cancer cell in a concentration-dependent manner $(p<0.05)$. Compound PS3 presented no evident photodynamic activity against $4 \mathrm{~T} 1$ cells. Interesting results were also obtained with PS5, which showed a significant phototoxicity against 4T1 cells but no activity against NIH-3T3 in PDT experiment, indicating that this compound might have a better selectivity towards the cancerous 4T1 cells tested in this study. However, further investigation on the selectivity of PS5 towards cancerous cells and the mechanism of action is warranted.

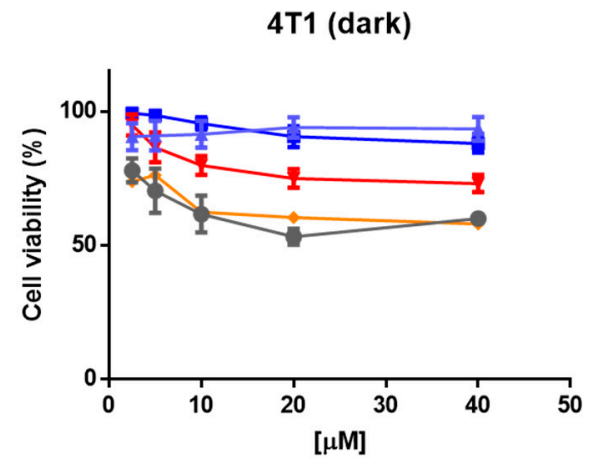

4T1 (PDT)

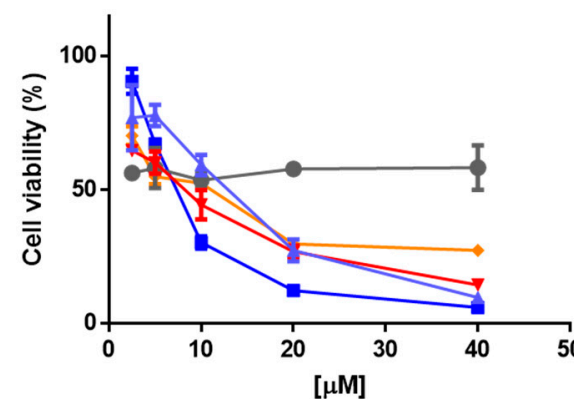

$\mp \mathrm{PS} 1 \rightarrow \mathrm{PS} 2$
NIH-3T3 (dark)

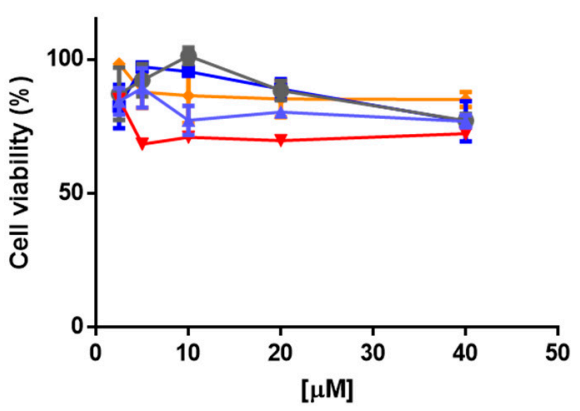

NIH-3T3 (PDT)

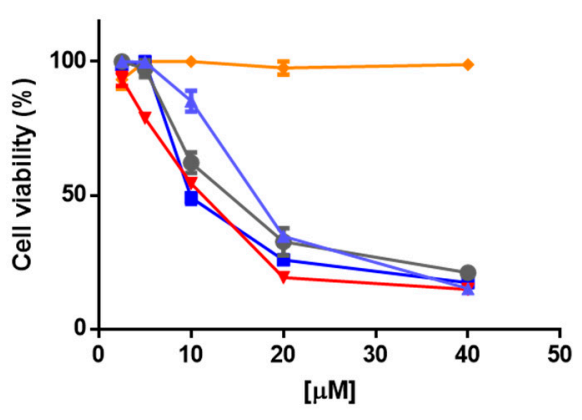

PS3 $\rightarrow$ PS4 $\rightarrow$ PS5

Figure 4. Toxicity of the compounds PS1 to PS5 at different concentrations against 4T1 and NIH-3T3 cells treated in the dark or irradiated with red light $\left(\lambda 660 \mathrm{~nm}, 25.8 \mathrm{~J} / \mathrm{cm}^{2}\right)$.

\section{Materials and Methods}

\subsection{General Information}

Dimethyl sulfoxide (DMSO), 1,3-diphenylisobenzofuran (DPBF) and Kholiphor ${ }^{\circledR}$ HS were obtained from Sigma (St. Louis, Missouri, USA). Roswell Park Memorial Institute (RPMI) medium and Dulbecco's modified Eagle medium (DMEM) were obtained from Gibco (Waltham, MA, USA). The 3-(4,5-dimethylthiazol-2yl)-2,5-diphenyltetrazolium bromide (MTT) was purchased from Invitrogen (Carlsbad, CA, USA). The phosphate buffered saline (PBS) was supplied by Laborclin (Rio de Janeiro, Brazil). Commercially available reagents were used without further purification. 
Organic solvents were evaporated with reduced pressure using Büchi evaporators. Reactions were monitored by TLC using Yantai JingYou (Yantai, China) GF254 silica gel plates. Silica gel column chromatography was performed on an Isolera One system (Biotage, Uppsala, Sweden), and silica gel (200-300 mesh) from Qingdao Hailang Inc. (Qingdao, China). NMR spectra were measured on an Avance III $600 \mathrm{MHz}$ spectrometer (Bruker, Fällanden, Switzerland). Chemical shifts were expressed in $\delta(\mathrm{ppm})$ and coupling constants $(J)$ in $\mathrm{Hz}$ using solvent signals as internal standards $\left(\mathrm{CDCl}_{3}, \delta_{\mathrm{H}} 7.26 \mathrm{ppm}\right.$ and $\delta_{\mathrm{C}} 77.2 \mathrm{ppm} ; \mathrm{CD}_{3} \mathrm{OD}, \delta_{\mathrm{H}} 3.31 \mathrm{ppm}$ and $\delta_{\mathrm{C}} 49.0 \mathrm{ppm} ; \mathrm{d}_{6}$-acetone, $\delta_{\mathrm{H}} 2.05 \mathrm{ppm}$ and $\delta_{\mathrm{C}} 29.8 \mathrm{ppm}$ ). ESI-MS were recorded on a 1260-6460 Triple Quad LC/MS (Agilent, Waldbronn, Germany) and HR-ESI-MS data were acquired on an Agilent Q-TOF 6520 system.

\subsection{Chemistry}

\subsubsection{Synthesis of 3-(Naphthalen-1-ylamino)propanoic Acid (2, $\left.\mathrm{C}_{13} \mathrm{H}_{13} \mathrm{NO}_{2}\right)$}

A mixture of naphthalen-1-amine 1 ( $2.0 \mathrm{~g}, 14.0 \mathrm{mmol}, 1$ equiv), 3-bromopropanoic acid ( $2.1 \mathrm{~g}$, $14.4 \mathrm{mmol}, 1$ equiv) and $\mathrm{Et}_{3} \mathrm{~N}(1.6 \mathrm{~g}, 14.4 \mathrm{mmol}, 1$ equiv) in $10 \mathrm{~mL} \mathrm{EtOH}$ was refluxed overnight. The solvent was then removed under reduced pressure. The crude product was purified by silica gel flash chromatography using $\mathrm{CH}_{2} \mathrm{Cl}_{2} / \mathrm{MeOH}$ (10:1) as eluent to give compound 2 as a white solid (1.0 g, $3.64 \mathrm{mmol}, 26 \%$ yield). ${ }^{1} \mathrm{H}-\mathrm{NMR}\left(\mathrm{CD}_{3} \mathrm{OD}\right): \delta 7.95(\mathrm{~d}, J=7.9 \mathrm{~Hz}, 1 \mathrm{H}), 7.73(\mathrm{~d}, J=7.8 \mathrm{~Hz}, 1 \mathrm{H}), 7.41-7.37$ $(\mathrm{m}, 2 \mathrm{H}), 7.29(\mathrm{dd}, J=7.6,8.1 \mathrm{~Hz}, 1 \mathrm{H}), 7.17(\mathrm{~d}, J=8.1 \mathrm{~Hz}, 1 \mathrm{H}), 6.63(\mathrm{~d}, J=7.6 \mathrm{~Hz}, 1 \mathrm{H}), 3.56(\mathrm{t}, J=6.8 \mathrm{~Hz}$, $2 \mathrm{H}), 2.74(\mathrm{t}, J=6.8 \mathrm{~Hz}, 2 \mathrm{H}) .{ }^{13} \mathrm{C}-\mathrm{NMR}\left(\mathrm{CD}_{3} \mathrm{OD}\right): \delta 176.3,144.8,135.9,129.3,127.6,126.6,125.4,125.3$, 121.7, 118.2, 105.2, 40.8, 34.4. ESI-MS m/z [M + H] calcd for $\mathrm{C}_{13} \mathrm{H}_{14} \mathrm{NO}_{2}{ }^{+}$216.1, found 216.2.

\subsubsection{Synthesis of 5-(Diethylamino)-2-nitrosophenol Hydrochloride $\left(4, \mathrm{C}_{10} \mathrm{H}_{15} \mathrm{ClN}_{2} \mathrm{O}_{2}\right)$}

A solution of 3-diethylaminophenol 3 ( $3.3 \mathrm{~g}, 20 \mathrm{mmol}, 1$ equiv) in a mixture of concentrated $\mathrm{HCl}$ $(7 \mathrm{~mL})$ and water $(7 \mathrm{~mL})$ was cooled to $0{ }^{\circ} \mathrm{C}$, and then a solution of sodium nitrite $(1.4 \mathrm{~g}, 20 \mathrm{mmol}$, 1 equiv) in water $(10 \mathrm{~mL})$ was added dropwise to the above mixture. The reaction was stirred at $0-5^{\circ} \mathrm{C}$ for $3.5 \mathrm{~h}$ to give a brown slurry. The slurry was filtered and washed with $4 \mathrm{M}$ aqueous $\mathrm{HCl}(6 \mathrm{~mL})$ to give compound 4 as a brown solid ( $3.0 \mathrm{~g}, 13 \mathrm{mmol}, 65 \%$ yield). This compound was used in the next step without further purification. ${ }^{1} \mathrm{H}-\mathrm{NMR}\left(\mathrm{CD}_{3} \mathrm{Cl}\right): \delta 7.37(\mathrm{~d}, J=8.0 \mathrm{~Hz}, 1 \mathrm{H}), 6.55(\mathrm{~m}, 1 \mathrm{H}), 5.70(\mathrm{~d}$, $J=4.2 \mathrm{~Hz}, 1 \mathrm{H}), 3.50(\mathrm{q}, J=8.0 \mathrm{~Hz}, 4 \mathrm{H}), 1.29(\mathrm{t}, J=8.0 \mathrm{~Hz}, 6 \mathrm{H}) .{ }^{13} \mathrm{C}-\mathrm{NMR}\left(\mathrm{CD}_{3} \mathrm{Cl}\right): \delta 169.6,157.4,149.8$, 135.8, 113.6, 96.3, 46.2, 13.5. ESI-MS m/z [M + H] calcd for $\mathrm{C}_{10} \mathrm{H}_{15} \mathrm{~N}_{2} \mathrm{O}_{2}{ }^{+}$195.1, found 195.2.

3.2.3. Synthesis of $\mathrm{N}$-Ethyl- $\mathrm{N}$-(5-(3-methoxy-3-oxopropylamino)-9H-benzo[ $a]$ phenoxazin-9-ylidene) ethanaminium Chloride (PS1, $\mathrm{C}_{24} \mathrm{H}_{26} \mathrm{ClN}_{3} \mathrm{O}_{3}$ )

To a cold (ice bath) solution of 4 (160 mg, $0.6 \mathrm{mmol}, 1.2$ equiv) in $\mathrm{MeOH}(10 \mathrm{~mL})$ was added 2 (100 mg, $0.5 \mathrm{mmol}, 1$ equiv) and 5 drop of concentrated $\mathrm{HCl}$. The mixture was refluxed for $4 \mathrm{~h}$. The solution was evaporated and purified by flash chromatography using $\mathrm{CH}_{2} \mathrm{Cl}_{2} / \mathrm{MeOH}$ (10:1) as eluent to give PS1 as a blue solid (45 mg, $0.12 \mathrm{mmol}, 24 \%$ yield). ${ }^{1} \mathrm{H}-\mathrm{NMR}\left(\mathrm{CD}_{3} \mathrm{OD}\right): \delta 8.83-8.80(\mathrm{~m}$, $1 \mathrm{H}), 8.29(\mathrm{~d}, J=8.0 \mathrm{~Hz}, 1 \mathrm{H}), 7.88(\mathrm{dd}, J=7.2,8.0 \mathrm{~Hz}, 1 \mathrm{H}), 7.81(\mathrm{dd}, J=5.0,9.3 \mathrm{~Hz}, 1 \mathrm{H}), 7.77(\mathrm{dd}, J=7.2$, $8.2 \mathrm{~Hz}, 1 \mathrm{H}), 7.28(\mathrm{~d}, J=9.3 \mathrm{~Hz}, 1 \mathrm{H}), 6.96(\mathrm{~s}, 1 \mathrm{H}), 6.89(\mathrm{~s}, 1 \mathrm{H}), 3.99(\mathrm{t}, J=6.7 \mathrm{~Hz}, 2 \mathrm{H}), 3.75(\mathrm{~s}, 3 \mathrm{H}), 3.71(\mathrm{q}$, $J=7.2 \mathrm{~Hz}, 4 \mathrm{H}), 2.96(\mathrm{t}, J=6.7 \mathrm{~Hz}, 2 \mathrm{H}), 1.35(\mathrm{t}, J=7.2 \mathrm{~Hz}, 6 \mathrm{H}) .{ }^{13} \mathrm{C}-\mathrm{NMR}\left(\mathrm{CD}_{3} \mathrm{OD}\right): \delta 173.2,159.1,155.9$, 153.1, 149.9, 134.7, 134.2, 132.9, 132.6, 132.1, 130.8, 125.2, 124.7, 123.8, 117.0, 97.0, 94.4, 52.5, 47.1, 41.4, 33.6, 13.0. ESI-MS $m / z$ [M] ${ }^{+}$404.3. HR-ESIMS: [M] ${ }^{+}$calcd for $\mathrm{C}_{24} \mathrm{H}_{26} \mathrm{~N}_{3} \mathrm{O}_{3}{ }^{+} 404.1969$, found 404.1967.

\subsubsection{Synthesis of $\mathrm{N}$-(2-Morpholinoethyl)-3-(naphthalen-1-ylamino)propanamide $\left(5, \mathrm{C}_{19} \mathrm{H}_{25} \mathrm{~N}_{3} \mathrm{O}_{2}\right.$ )}

Compound 2 (100 mg, $0.5 \mathrm{mmol}, 1$ equiv) was dissolved in $\mathrm{CH}_{2} \mathrm{Cl}_{2}(10 \mathrm{~mL})$, and then 2-morpholinoethanamine (120 mg, 0.9 mmol, 1.8 equiv), HATU (200 mg, $0.5 \mathrm{mmol}, 1$ equiv) and $i \mathrm{PrNEt}_{2}$ ( $0.2 \mathrm{~mL}, 1 \mathrm{mmol}, 2$ equiv) was added. The mixture was stirred overnight, and then concentrated. The residue was purified by silica gel chromatography with petroleum ether/acetone (1:1) as eluent to give compound 5 as a white solid $\left(128 \mathrm{mg}, 0.42 \mathrm{mmol}, 84 \%\right.$ yield). ${ }^{1} \mathrm{H}-\mathrm{NMR}\left(\mathrm{CDCl}_{3}\right): \delta 7.83(\mathrm{~d}$, 
$J=8.0 \mathrm{~Hz}, 1 \mathrm{H}), 7.78(\mathrm{~d}, J=9.2 \mathrm{~Hz}, 1 \mathrm{H}), 7.45-7.41(\mathrm{~m}, 2 \mathrm{H}), 7.35(\mathrm{dd}, J=7.5,8.2 \mathrm{~Hz}, 1 \mathrm{H}), 7.25(\mathrm{~d}, J=8.2 \mathrm{~Hz}$, $1 \mathrm{H}), 6.54(\mathrm{~d}, J=7.5 \mathrm{~Hz}, 1 \mathrm{H}), 6.27(\mathrm{brs}, 1 \mathrm{H}), 5.07(\mathrm{brs}, 1 \mathrm{H}), 3.64(\mathrm{t}, J=6.0 \mathrm{~Hz}, 2 \mathrm{H}), 3.50(\mathrm{brs}, 4 \mathrm{H}), 3.32(\mathrm{t}$, $J=6.0 \mathrm{~Hz}, 2 \mathrm{H}), 2.64(\mathrm{~d}, J=6.0 \mathrm{~Hz}, 2 \mathrm{H}), 2.38(\mathrm{t}, J=6.0 \mathrm{~Hz}, 2 \mathrm{H}), 2.29(\mathrm{brs}, 4 \mathrm{H}) .{ }^{13} \mathrm{C}-\mathrm{NMR}\left(\mathrm{CDCl}_{3}\right): \delta$ 171.8, 142.9, 134.4, 128.6, 126.5, 125.8, 124.8, 123.7, 120.0, 117.7, 104.4, 66.7, 56.8, 53.2, 40.3, 35.5, 35.3 . ESI-MS $m / z:[\mathrm{M}+\mathrm{H}]^{+}$calcd for $\mathrm{C}_{19} \mathrm{H}_{25} \mathrm{~N}_{3} \mathrm{O}_{2}{ }^{+} 328.2$, found 328.3.

3.2.5. Synthesis of $\mathrm{N}$-Ethyl- $\mathrm{N}$-(5-(3-(2-morpholinoethylamino)-3-oxopropylamino)-9H-benzo[ $a]$ phenoxazin-9-ylidene)ethanaminium Chloride (PS2, $\mathrm{C}_{29} \mathrm{H}_{36} \mathrm{ClN}_{5} \mathrm{O}_{3}$ )

To a cold solution of compound 4 ( $50 \mathrm{mg}, 0.2 \mathrm{mmol}, 1$ equiv) in $\mathrm{EtOH}(5 \mathrm{~mL})$ was added compound 5 (60 mg, $0.2 \mathrm{mmol}, 1$ equiv) and 5 drops of concentrated $\mathrm{HCl}$. The mixture was refluxed for $4 \mathrm{~h}$. The solution was evaporated and purified by silica gel flash chromatography using $\mathrm{CH}_{2} \mathrm{Cl}_{2} / \mathrm{MeOH}$ (10:1) as eluent to give compound PS2 as a blue solid (54 mg, $0.11 \mathrm{mmol}, 55 \%$ yield). ${ }^{1} \mathrm{H}-\mathrm{NMR}$ $\left(\mathrm{CD}_{3} \mathrm{OD}\right): \delta 8.72(\mathrm{~s}, 1 \mathrm{H}), 8.39(\mathrm{~s}, 1 \mathrm{H}), 7.84(\mathrm{~s}, 1 \mathrm{H}), 7.75(\mathrm{~s}, 2 \mathrm{H}), 7.25(\mathrm{~s}, 1 \mathrm{H}), 6.85(\mathrm{~s}, 1 \mathrm{H}), 4.04-3.96(\mathrm{~m}, 6 \mathrm{H})$, $3.70-3.66(\mathrm{~m}, 8 \mathrm{H}), 3.34(\mathrm{~s}, 2 \mathrm{H}), 3.18(\mathrm{~s}, 2 \mathrm{H}), 2.91(\mathrm{~s}, 2 \mathrm{H}), 1.35(\mathrm{~s}, 6 \mathrm{H}) .{ }^{13} \mathrm{C}-\mathrm{NMR}\left(\mathrm{CD}_{3} \mathrm{OD}\right): \delta 174.1,158.9$, $155.8,152.9,149.7,134.5,134.2,132.9,132.3,131.9,130.8,125.4,124.5,124.2,117.0,96.9,94.6,64.8,58.1$, 53.4, 41.8, 35.1, 34.7, 13.0. ESI-MS $m / z$ [M] ${ }^{+}$502.2. HR-ESIMS: $[\mathrm{M}]^{+}$calcd for $\mathrm{C}_{29} \mathrm{H}_{36} \mathrm{~N}_{5} \mathrm{O}_{3}{ }^{+}$502.2813, found 502.2812; $[\mathrm{M}+\mathrm{H}]^{2+}$ calcd for $\mathrm{C}_{29} \mathrm{H}_{36} \mathrm{~N}_{5} \mathrm{O}_{3}{ }^{2+}$ 251.6442, found 251.6445.

3.2.6. Synthesis of tert-Butyl 2-(3-(naphthalen-1-ylamino)propanamido)ethylcarbamate $\left(6, \mathrm{C}_{20} \mathrm{H}_{27} \mathrm{~N}_{3} \mathrm{O}_{3}\right)$

Compound 2 (100 mg, $0.5 \mathrm{mmol}, 1$ equiv) was dissolved in $\mathrm{CH}_{2} \mathrm{Cl}_{2}(10 \mathrm{~mL})$, and then tert-butyl (2-aminoethyl)carbamate ( $149 \mathrm{mg}, 1.0 \mathrm{mmol}, 2$ equiv), HATU ( $200 \mathrm{mg}, 0.5 \mathrm{mmol}, 1$ equiv) and $i$ PrNEt $_{2}$ ( $0.2 \mathrm{~mL}, 1 \mathrm{mmol}, 2$ equiv) was added. The mixture was stirred overnight, and then concentrated. The residue was purified by silica gel chromatography with $\mathrm{CH}_{2} \mathrm{Cl}_{2} / \mathrm{MeOH}(10: 1)$ as eluent to give compound 6 as a white solid $\left(160 \mathrm{mg}, 0.48 \mathrm{mmol}, 96 \%\right.$ yield). ${ }^{1} \mathrm{H}-\mathrm{NMR}\left(\mathrm{CDCl}_{3}\right): \delta 7.91-7.89(\mathrm{~m}, 1 \mathrm{H})$, 7.79-7.77 (m, 1H), 7.45-7.41 (m, 2H), 7.46-7.43 (m, 1H), 7.34 (dd, J = 7.6, 8.0 Hz, 1H), 7.27 (d, J = 7.0 Hz, $1 \mathrm{H}), 6.6(\mathrm{~d}, J=7.6 \mathrm{~Hz}, 1 \mathrm{H}), 6.48(\mathrm{brs}, 1 \mathrm{H}), 4.85(\mathrm{brs}, 1 \mathrm{H}), 3.61(\mathrm{t}, J=6.0 \mathrm{~Hz}, 2 \mathrm{H}), 3.37-3.34(\mathrm{~m}, 2 \mathrm{H})$, 3.26-3.24 (m, 2H), $2.63(\mathrm{t}, J=6.0 \mathrm{~Hz}, 2 \mathrm{H}), 1.41(\mathrm{~s}, 9 \mathrm{H}) .{ }^{13} \mathrm{C}-\mathrm{NMR}\left(\mathrm{CDCl}_{3}\right): \delta 172.6,157.2,142.9,134.5$, $128.7,126.6,126.0,125.1,124.0,120.3,118.2,105.0,80.0,41.1,40.8,40.3,35.2,28.4$. ESI-MS $m / z:[\mathrm{M}+\mathrm{H}]^{+}$ calcd for $\mathrm{C}_{20} \mathrm{H}_{28} \mathrm{~N}_{3} \mathrm{O}_{3}{ }^{+} 484.2$, found 358.0.

3.2.7. Synthesis of $\mathrm{N}$-(2-(3-(Naphthalen-1-ylamino)propanamido)ethyl)-5-(2-oxohexahydro-1H -thieno[3,4-d]imidazol-4-yl)pentanamide $\left(7, \mathrm{C}_{25} \mathrm{H}_{33} \mathrm{~N}_{5} \mathrm{O}_{3} \mathrm{~S}\right)$

To a cold (ice bath) solution of 6 (120 mg, $0.34 \mathrm{mmol}, 1$ equiv) in $\mathrm{CH}_{2} \mathrm{Cl}_{2}(5 \mathrm{~mL})$ was added trifluoroacetic acid $\left(100 \mu \mathrm{L}, 1 \mathrm{mmol}, 2.9\right.$ equiv) under $0{ }^{\circ} \mathrm{C}$. The mixture was stirred overnight, and then concentrated to give a residue, which was used in the next step without further purification. The obtained residue was dissolved in $\mathrm{CH}_{3} \mathrm{CN}(5 \mathrm{~mL})$, and then Biotin-NHS (172 mg, $0.50 \mathrm{mmol}$, 1.5 equiv), and $\mathrm{Et}_{3} \mathrm{~N}$ (0.2 mL, $1 \mathrm{mmol}, 2.9$ equiv) were added. The mixture was stirred overnight, and then concentrated. The residue was purified by silica gel chromatography with $\mathrm{CH}_{2} \mathrm{Cl}_{2} / \mathrm{MeOH}$ (10:1) as eluent to give compound 7 as a white solid $\left(85 \mathrm{mg}, 0.18 \mathrm{mmol}, 52 \%\right.$ yield). ${ }^{1} \mathrm{H}-\mathrm{NMR}$ (DMSO- $\left.d_{6}\right): \delta 8.08(\mathrm{~d}, J=8.3 \mathrm{~Hz}, 1 \mathrm{H}), 7.99(\mathrm{brs}, 1 \mathrm{H}), 7.81(\mathrm{brs}, 1 \mathrm{H}), 7.75(\mathrm{~d}, J=8.3 \mathrm{~Hz}, 1 \mathrm{H}), 7.43(\mathrm{ddd}$, $J=1.0,6.7,8.4 \mathrm{~Hz}, 1 \mathrm{H}), 7.39(\mathrm{ddd}, J=1.4,6.8,9.0 \mathrm{~Hz}, 1 \mathrm{H}), 7.29(\mathrm{dd}, J=7.8,7.9 \mathrm{~Hz}, 1 \mathrm{H}), 7.11(\mathrm{~d}, J=8.2 \mathrm{~Hz}$, $1 \mathrm{H}), 6.54(\mathrm{~d}, J=8.6 \mathrm{~Hz}, 1 \mathrm{H}), 6.42(\mathrm{~s}, 1 \mathrm{H}), 6.35(\mathrm{~s}, 1 \mathrm{H}), 6.19(\mathrm{dd}, J=5.4,5.5 \mathrm{~Hz}, 1 \mathrm{H}), 4.28-4.26(\mathrm{~m}, 1 \mathrm{H})$, $4.11-4.09(\mathrm{~m}, 1 \mathrm{H}), 3.44-3.41(\mathrm{~m}, 1 \mathrm{H}), 3.31(\mathrm{~m}, 5 \mathrm{H}), 2.78(\mathrm{dd}, J=5.1,12.5 \mathrm{~Hz}, 1 \mathrm{H}), 2.56(\mathrm{~d}, J=12.5 \mathrm{~Hz}$, $1 \mathrm{H}), 2.04(\mathrm{t}, J=1.1 \mathrm{~Hz}, 1 \mathrm{H}), 1.61-1.57(\mathrm{~m}, 1 \mathrm{H}), 1.53-1.43(\mathrm{~m}, 3 \mathrm{H}), 1.32-1.23(\mathrm{~m}, 2 \mathrm{H}), 1.17(\mathrm{t}, J=7.3 \mathrm{~Hz}$, 1H). ${ }^{13}$ C-NMR (DMSO- $d_{6}$ ): $\delta$ 172.4, 171.1, 162.7, 143.8, 134.0, 127.9, 126.8, 125.6, 124.0, 123.0, 121.4, 115.6, $102.9,61.0,59.2,55.4,45.7,40.1,38.5,38.3,35.3,34.8,28.2,28.0,25.2$. ESI-MS $m / z:[\mathrm{M}+\mathrm{H}]^{+}$calcd for $\mathrm{C}_{25} \mathrm{H}_{34} \mathrm{~N}_{5} \mathrm{O}_{3} \mathrm{~S}^{+} 484.2$, found 484.3 . 
3.2.8. Synthesis of N-Ethyl-N-(5-(3-oxo-3-(2-(5-(2-oxohexahydro-1H-thieno[3,4-d]imidazol-4-yl) pentanamido)ethylamino)propylamino)-9H-benzo[a]phenoxazin-9-ylidene)ethanaminium Chloride (PS3, $\mathrm{C}_{35} \mathrm{H}_{44} \mathrm{ClN}_{7} \mathrm{O}_{4} \mathrm{~S}$ )

To a cold solution of 4 (50 mg, $0.2 \mathrm{mmol}, 1$ equiv) in $\mathrm{EtOH}(5 \mathrm{~mL})$ was added 7 (60 mg, $1.2 \mathrm{mmol}$, 6 equiv) and 5 drops of concentrated $\mathrm{HCl}$. The mixture was refluxed for $4 \mathrm{~h}$. The solution was evaporated and purified by silica gel flash chromatography using $\mathrm{CH}_{2} \mathrm{Cl}_{2} / \mathrm{MeOH}(10: 1)$ as eluent to give PS3 as a blue solid (53 mg, $0.12 \mathrm{mmol}, 62 \%$ yield). ${ }^{1} \mathrm{H}-\mathrm{NMR}\left(\mathrm{CD}_{3} \mathrm{OD}\right): \delta 8.89-8.83(\mathrm{~m}, 1 \mathrm{H}), 8.37(\mathrm{~d}$, $J=7.5 \mathrm{~Hz}, 1 \mathrm{H}), 7.89-7.79(\mathrm{~m}, 2 \mathrm{H}), 7.75-7.55(\mathrm{~m}, 2 \mathrm{H}), 7.29(\mathrm{~d}, J=9.0 \mathrm{~Hz}, 1 \mathrm{H}), 7.01(\mathrm{~s}, 1 \mathrm{H}), 6.91(\mathrm{~s}, 1 \mathrm{H})$, $4.46(\mathrm{~s}, 1 \mathrm{H}), 4.28(\mathrm{~s}, 1 \mathrm{H}), 4.01(\mathrm{~s}, 1 \mathrm{H}), 3.72-3.71(\mathrm{~m}, 4 \mathrm{H}), 3.56(\mathrm{~s}, 1 \mathrm{H}), 3.15(\mathrm{~s}, 1 \mathrm{H}), 2.89-2.74(\mathrm{~m}, 2 \mathrm{H}), 2.66$ $(\mathrm{s}, 1 \mathrm{H}), 2.15(\mathrm{~s}, 1 \mathrm{H}), 1.67-1.51(\mathrm{~m}, 4 \mathrm{H}), 1.35(\mathrm{t}, J=7.0 \mathrm{~Hz}, 1 \mathrm{H}), 1.17-1.14(\mathrm{~m}, 2 \mathrm{H}) .{ }^{13} \mathrm{C}-\mathrm{NMR}\left(\mathrm{CD}{ }_{3} \mathrm{OD}\right): \delta$ 176.4, 173.2, 159.1, 155.8, 153.2, 149.8, 134.7, 134.3, 132.9, 132.6, 132.1, 130.9, 125.5, 124.7, 124.0, 121.7, 117.0, 97.0, 94.5, 63.3, 61.6, 56.9, 47.1, 42.0, 41.0, 40.4, 39.9, 36.7, 35.5, 29.7, 29.4, 26.7, 13.0. ESI-MS $m / z$ $[\mathrm{M}]^{+}$658.2. HR-ESIMS: $[\mathrm{M}]^{+}$calcd for $\mathrm{C}_{35} \mathrm{H}_{44} \mathrm{~N}_{7} \mathrm{O}_{4} \mathrm{~S}^{+} 658.3170$, found 658.3171 .

3.2.9. Synthesis of $(3 S, 10 R, 13 S, 17 S)-17$-Acetyl-10,13-dimethyl-2,3,4,7,8,9,10,11,12,13,14,15,16,17tetradecahydro- $1 H$-cyclopenta[a]phenanthren-3-yl 2-(3-(naphthalen-1-ylamino)propanamido) ethylcarbamate $\left(9, \mathrm{C}_{37} \mathrm{H}_{49} \mathrm{~N}_{3} \mathrm{O}_{4}\right)$

To a solution of $(3 S, 10 R, 13 S, 17 S)$-17-acetyl-10,13-dimethyl-2,3,4,7,8,9,10,11,12,13,14,15,16,17tetradecahydro-1H-cyclopenta[a]phenanthren-3-yl 2-(tert-butoxycarbonylamino)ethylcarbamate (8, $300 \mathrm{mg}, 0.6 \mathrm{mmol}, 1$ equiv) in $\mathrm{CH}_{2} \mathrm{Cl}_{2}(10 \mathrm{~mL})$ was added trifluoroacetic acid ( $300 \mu \mathrm{L}, 3 \mathrm{mmol}, 5$ equiv) under $0{ }^{\circ} \mathrm{C}$. The mixture was stirred overnight, and then concentrated to give a residue, which was used in the next step without further purification. The above residue was dissolved in $\mathrm{CH}_{2} \mathrm{Cl}_{2},(10 \mathrm{~mL})$ and then compound 2 (128 mg, $0.6 \mathrm{mmol}, 1$ equiv), HATU (248 mg, $0.7 \mathrm{mmol}, 1.1$ equiv) and $i \mathrm{PrNEt}_{2}$ ( $0.2 \mathrm{~mL}, 1 \mathrm{mmol}, 2$ equiv) were added. The mixture was stirred overnight, and then concentrated. The residue was purified by silica gel chromatography with petroleum ether/acetone (1:1) as eluent to give compound 9 as a white solid $(205 \mathrm{mg}, 0.34 \mathrm{mmol}, 57 \%) .{ }^{1} \mathrm{H}-\mathrm{NMR}\left(\mathrm{CDCl}_{3}\right): \delta 7.87(\mathrm{~d}, J=7.5 \mathrm{~Hz}$, $1 \mathrm{H}), 7.78(\mathrm{~m}, 2 \mathrm{H}), 7.46-7.42(\mathrm{~m}, 2 \mathrm{H}), 7.34(\mathrm{dd}, J=7.9,7.8 \mathrm{~Hz}, 1 \mathrm{H}), 7.25(\mathrm{~d}, J=8.2 \mathrm{~Hz}, 1 \mathrm{H}), 6.62(\mathrm{~d}$, $J=7.5 \mathrm{~Hz}, 1 \mathrm{H}), 5.34(\mathrm{~s}, 1 \mathrm{H}), 5.15(\mathrm{~s}, 1 \mathrm{H}), 4.95(\mathrm{~s}, 1 \mathrm{H}), 3.62-3.60(\mathrm{~m}, 2 \mathrm{H}), 3.36(\mathrm{~d}, J=5.4 \mathrm{~Hz}, 1 \mathrm{H}), 2.62$ $(\mathrm{dd}, J=6.1,6.1 \mathrm{~Hz}, 1 \mathrm{H}), 2.53(\mathrm{dd}, J=9.1,8.8 \mathrm{~Hz}, 1 \mathrm{H}), 2.20-2.14(\mathrm{~m}, 3 \mathrm{H}), 2.12(\mathrm{~s}, 3 \mathrm{H}), 2.05-1.96(\mathrm{~m}, 2 \mathrm{H})$, 1.83-1.82 (m, 2H), 1.68-1.43 (m, 9H), 1.25-1.21 (m, 1H), 1.15-1.09 (m, 1H), $0.98(\mathrm{~s}, 3 \mathrm{H}), 0.62(\mathrm{~s}, 3 \mathrm{H})$. ${ }^{13} \mathrm{C}-\mathrm{NMR}\left(\mathrm{CDCl}_{3}\right): \delta$ 209.8, 172.7, 157.3, 143.6, 139.8, 134.5, 128.7, 126.6, 126.0, 125.0, 123.9, 122.4, 120.3, $117.9,104.6,74.8,63.8,57.0,50.0,44.1,40.9,40.7,40.5,38.9,38.6,37.1,36.7,35.4,31.9,31.9,31.7,28.2$, 24.6, 23.0, 21.1, 19.4, 13.4. ESI-MS $m / z$ : $[\mathrm{M}+\mathrm{H}]^{+}$calcd for $\mathrm{C}_{37} \mathrm{H}_{50} \mathrm{~N}_{3} \mathrm{O}_{4}{ }^{+}$600.4, found 600.1.

3.2.10. Synthesis of $N-(5-(3-(2-(((3 S, 10 R, 13 S, 17 S)-17-A c e t y l-10,13-$ dimethyl-2,3,4,7,8,9,10,11,12,13,14, 15,16,17-tetradecahydro-1H-cyclopenta[a]phenanthren-3-yloxy)carbonylamino)ethylamino)-3oxopropylamino)-9H-benzo[a]phenoxazin-9-ylidene)- $\mathrm{N}$-ethylethanaminium Chloride (PS4, $\mathrm{C}_{47} \mathrm{H}_{60} \mathrm{ClN}_{5} \mathrm{O}_{5}$ )

To a cold (ice bath) solution of compound 4 ( $30 \mathrm{mg}, 0.13 \mathrm{mmol}, 1.6$ equiv) in EtOH $(5 \mathrm{~mL})$ was added compound 9 (50 mg, $0.08 \mathrm{mmol}, 1$ equiv) and 5 drops of concentrated $\mathrm{HCl}$. The mixture was refluxed for $4 \mathrm{~h}$. The solution was evaporated and purified by silica gel flash chromatography using $\mathrm{CH}_{2} \mathrm{Cl}_{2} / \mathrm{MeOH}(10: 1)$ as eluent to give compound PS4 as a blue solid (45 $\mathrm{mg}, 0.06 \mathrm{mmol}, 69 \%$ yield). ${ }^{1} \mathrm{H}-\mathrm{NMR}\left(\mathrm{CD}_{3} \mathrm{OD}\right): \delta 8.82(\mathrm{~d}, J=11 \mathrm{~Hz}, 1 \mathrm{H}), 8.31(\mathrm{dd}, J=8.3,8.4 \mathrm{~Hz}, 1 \mathrm{H}), 7.88(\mathrm{dd}, J=7.4,7.6 \mathrm{~Hz}$, $1 \mathrm{H}), 7.82(\mathrm{~d}, J=9.2 \mathrm{~Hz}, 1 \mathrm{H}), 7.79(\mathrm{dd}, J=7.3,7.6 \mathrm{~Hz}, 1 \mathrm{H}), 7.28(\mathrm{~d}, J=8.7 \mathrm{~Hz}, 1 \mathrm{H}), 6.99(\mathrm{~s}, 1 \mathrm{H}), 6.89(\mathrm{~s}$, $1 \mathrm{H}), 5.02(\mathrm{~s}, 1 \mathrm{H}), 4.23(\mathrm{~m}, 1 \mathrm{H}), 3.99-3.97(\mathrm{~m}, 2 \mathrm{H}), 3.72-3.69(\mathrm{~m}, 4 \mathrm{H}), 2.79-2.77(\mathrm{~m}, 2 \mathrm{H}), 2.55(\mathrm{dd}, J=6.7$, $7.0 \mathrm{~Hz}, 1 \mathrm{H}), 2.15-2.08(\mathrm{~m}, 5 \mathrm{H}), 1.98(\mathrm{~d}, J=8.2 \mathrm{~Hz}, 1 \mathrm{H}), 1.73-1.60(\mathrm{~m}, 6 \mathrm{H}), 1.83-1.82(\mathrm{~m}, 2 \mathrm{H}), 1.38(\mathrm{~d}$, $J=6.7 \mathrm{~Hz}, 1 \mathrm{H}), 1.35(\mathrm{t}, J=7.2 \mathrm{~Hz}, 1 \mathrm{H}), 0.82(\mathrm{~s}, 3 \mathrm{H}), 0.52(\mathrm{~s}, 3 \mathrm{H}) .{ }^{13} \mathrm{C}-\mathrm{NMR}\left(\mathrm{CD}_{3} \mathrm{OD}\right): \delta 212.1,173.4$, $159.0,158.9,155.7,153.0,149.7,141.1,141.1,134.2,132.9,132.6,130.9,125.6,125.5,124.1,124.0,123.0$, 116.8, 97.1, 94.7, 75.3, 64.6, 57.9, 51.2, 47.1, 44.9, 41.1, 39.7, 38.0, 37.5, 36.1, 35.6, 35.5, 33.0, 32.9, 32.6, 31.7, 29.1, 25.4, 23.7, 22.0, 19.6, 13.5, 13.0. ESI-MS $m / z$ : [M] ${ }^{+}$774.4. HR-ESIMS: $[M]^{+}$calcd for $\mathrm{C}_{47} \mathrm{H}_{60} \mathrm{~N}_{5} \mathrm{O}_{5}{ }^{+}$ 774.4589 , found 774.4595 . 
3.2.11. Synthesis of $N, N^{\prime}$-(Ethane-1,2-diyl)bis(3-(naphthalen-1-ylamino)propanamide) $\left(10, \mathrm{C}_{28} \mathrm{H}_{30} \mathrm{~N}_{4} \mathrm{O}_{2}\right)$

To a solution (ice bath) of compound 6 (170 mg, $0.5 \mathrm{mmol}$, equiv) in $\mathrm{CH}_{2} \mathrm{Cl}_{2}$ (5 mL) was added trifluoroacetic acid $\left(500 \mu \mathrm{L}, 5 \mathrm{mmol}, 14.5\right.$ equiv) under $0{ }^{\circ} \mathrm{C}$. The mixture was stirred overnight, and then concentrated to give a residue, which was used in the next step without further purification. The above residue was dissolved in $\mathrm{CH}_{2} \mathrm{Cl}_{2}(5 \mathrm{~mL})$ and then compound 2 (102 $\mathrm{mg}, 0.5 \mathrm{mmol}, 1$ equiv), HATU ( $200 \mathrm{mg}, 0.5 \mathrm{mmol}, 1$ equiv) and $i \operatorname{PrNEt}_{2}(0.2 \mathrm{~mL}, 1 \mathrm{mmol}, 2$ equiv) were added. The mixture was stirred overnight, and then concentrated. The residue was purified by silica gel chromatography with $\mathrm{CH}_{2} \mathrm{Cl}_{2} / \mathrm{MeOH}$ (20:1) as eluent to give compound 10 as a white solid (185 mg, $0.44 \mathrm{mmol}, 87 \%$ yield). ${ }^{1} \mathrm{H}-\mathrm{NMR}\left(d_{6}\right.$-acetone): $\delta 8.40(\mathrm{~d}, J=8.4 \mathrm{~Hz}, 1 \mathrm{H}), 7.76(\mathrm{~d}, J=8.4 \mathrm{~Hz}, 1 \mathrm{H}), 7.41-7.38(\mathrm{~m}, 3 \mathrm{H})$, $7.29(\mathrm{dd}, J=7.9,7.9 \mathrm{~Hz}, 1 \mathrm{H}), 7.15(\mathrm{~d}, J=8.2 \mathrm{~Hz}, 1 \mathrm{H}), 6.59(\mathrm{~d}, J=7.4 \mathrm{~Hz}, 1 \mathrm{H}), 5.84(\mathrm{~s}, 1 \mathrm{H}), 3.52(\mathrm{t}$, $J=6.4 \mathrm{~Hz}, 2 \mathrm{H}), 3.30(\mathrm{t}, J=2.6 \mathrm{~Hz}, 2 \mathrm{H}), 2.57(\mathrm{~d}, J=6.4 \mathrm{~Hz}, 2 \mathrm{H}) .{ }^{13} \mathrm{C}-\mathrm{NMR}\left(d_{6}\right.$-acetone): $\delta 172.9,144.9$, 135.5, 129.1, 127.6, 126.4, 125.1, 124.6, 121.7, 117.2, 104.4, 41.1, 40.1, 35.7. ESI-MS $m / z:[\mathrm{M}+\mathrm{H}]^{+}$calcd for $\mathrm{C}_{28} \mathrm{H}_{31} \mathrm{~N}_{4} \mathrm{O}_{2}{ }^{+} 455.2$, found 455.1 .

3.2.12. Synthesis of di(N-(5-(3-(2-Aminoethylamino)-3-oxopropylamino)-9H-benzo[a]phenoxazin-9ylidene))- $N$, $N^{\prime}$-ethylethanaminium Dichloride (PS5, $\mathrm{C}_{48} \mathrm{H}_{52} \mathrm{Cl}_{2} \mathrm{~N}_{8} \mathrm{O}_{4}$ )

To a cold solution of compound $4(125 \mathrm{mg}, 0.5 \mathrm{mmol}, 1$ equiv) in $\mathrm{EtOH}(5 \mathrm{~mL})$ was added compound 10 (100 mg, $0.2 \mathrm{mmol}, 1$ euqiv) and 5 drops of concentrated $\mathrm{HCl}$. The mixture was refluxed for $4 \mathrm{~h}$. The solution was evaporated and purified by silica gel flash chromatography using $\mathrm{CH}_{2} \mathrm{Cl}_{2} / \mathrm{MeOH}$ (10:1) as eluent to give compound PS5 as a purple solid ( $80 \mathrm{mg}, 0.22 \mathrm{mmol}, 45 \%$ yield). ${ }^{1} \mathrm{H}-\mathrm{NMR}\left(\mathrm{CD}_{3} \mathrm{OD}\right): \delta 8.29(\mathrm{~d}, J=7.9 \mathrm{~Hz}, 1 \mathrm{H}), 8.26(\mathrm{~d}, J=8.0 \mathrm{~Hz}, 1 \mathrm{H}), 7.65(\mathrm{dd}, J=7.3,7.6 \mathrm{~Hz}, 1 \mathrm{H}), 7.57$ $(\mathrm{dd}, J=7.3,9.3 \mathrm{~Hz}, 1 \mathrm{H}), 7.47(\mathrm{~d}, J=9.3 \mathrm{~Hz}, 1 \mathrm{H}), 7.11(\mathrm{~d}, J=9.2 \mathrm{~Hz}, 1 \mathrm{H}), 6.61(\mathrm{~s}, 1 \mathrm{H}), 6.58(\mathrm{~s}, 1 \mathrm{H}), 3.74(\mathrm{~s}$, $2 \mathrm{H}), 3.64(\mathrm{q}, J=7.1 \mathrm{~Hz}, 4 \mathrm{H}), 3.40(\mathrm{~s}, 2 \mathrm{H}), 2.81(\mathrm{~s}, 2 \mathrm{H}), 1.34(\mathrm{t}, J=7.1 \mathrm{~Hz}, 6 \mathrm{H}) .{ }^{13} \mathrm{C}-\mathrm{NMR}\left(\mathrm{CD}_{3} \mathrm{OD}\right): \delta$ 173.5, 158.4, 155.6, 152.2, 149.1, 134.0, 133.9, 132.8, 131.9, 131.5, 130.7, 125.1, 124.2, 124.2, 116.9, 96.9, 94.4, 47.2, 42.2, 40.3, 35.1, 13.1. ESI-MS $m / z$ [M] ${ }^{2+}$ 402.3. HR-ESIMS: $[\mathrm{M}]^{2+}$ calcd for $\mathrm{C}_{48} \mathrm{H}_{52} \mathrm{~N}_{8} \mathrm{O}_{4}{ }^{2+} 402.2050$, found 402.2049 .

\subsection{General Spectroscopic Measurements}

Absorption spectra were recorded in a Shimadzu UV-2600 Spectrophotometer (Shimadzu, Kyoto, Japan). Fluorescence measurements were performed using an Agilent Cary Eclipse (Varian, Palo Alto, California, USA). The concentrations of all the compounds were $5 \mu \mathrm{M}$. Fluorescence spectra were corrected for the instrumental response of the system. All solutions were prepared using Milli-Q grade water. The fluorescence quantum yields $(\varphi)$ were determined according to the method Equation (1) below:

$$
\varphi_{u}=\varphi_{s} \times\left(\mathrm{F}_{u} / \mathrm{F}_{s}\right) \times\left(\mathrm{A}_{s} / \mathrm{A}_{u}\right) \times\left(\eta_{u} / \eta_{s}\right)^{2}
$$

where $\varphi$ is fluorescence quantum yield; $F$ is integrated area under the corrected emission spectra; $\eta$ is the refractive index of the solution; $A$ is the absorbance at the excitation wavelength; the subscripts $u$ and $\mathrm{s}$ refer to the unknown and the standard, respectively. We chose fluorescein in water as reference, $\varphi_{s}=0.98$.

\subsection{ROS Detection}

To evaluate the capacity of the compounds to produce singlet oxygen, the DPBF method was used. Briefly, $200 \mu \mathrm{L}$-aliquots of compounds in DMSO $(40 \mu \mathrm{M})$ were plated in 96-well plates. Then, $10 \mu \mathrm{L}$ of a solution of DPBF in ethanol $(0.22 \mathrm{mg} / \mathrm{mL})$ were added to each aliquot. Controls consisted of each compound without DPBF, and DPBF alone. Then, the microplate was irradiated every $10 \mathrm{~s}$ using 660 nm LED (Light Emitting Diode, XL001WP01NRC660, Shenzhen S. O. Co, Shenzhen, China). The optical density of the DPBF solution at $414 \mathrm{~nm}$ was used as an index of ROS production, as the DPBF is degraded by ROS and its light absorption at this wavelength is thus decreased. 


\subsection{Phototoxicity Assay}

The toxicity of different treatments against 4T1 and NIH-3T3 cells was measured by an MTT assay. Briefly, 4T1 and NIH-3T3, $1 \times 10^{4}$ cells per well, were treated with different concentrations of the compounds for $30 \mathrm{~min}$, in RPMI and DMEM, respectively, and then washed twice with PBS. After, the microplates were: (1) maintained in the dark; or (2) irradiated with a light emitting diode (LED, $\lambda 660 \mathrm{~nm}$ ) at a final energy density of $25.8 \mathrm{~J} / \mathrm{cm}^{2}$. The control consisted of cells that received only culture medium. Next, the cells were washed with PBS, cultured for further $24 \mathrm{~h}$, and then the culture medium was replaced by a $0.5 \mathrm{mg} / \mathrm{mL}$ MTT solution in culture medium. The cells were then incubated for $2.5 \mathrm{~h}$ at $37^{\circ} \mathrm{C}$ in a $5 \% \mathrm{CO}_{2}$, humid atmosphere. The MTT solution was then discarded, the formazan produced by the viable cells was extracted with $200 \mu \mathrm{L}$ DMSO, and the optical density was read at $\lambda 595 \mathrm{~nm}$ with a microplate spectrophotometer. This experiment was performed in triplicate for each treatment, and the results were expressed as percentages relative to control.

\subsection{Statistical Analysis}

Data were analyzed by one-way ANOVA, with Sidak's post-test $(\alpha=0.05)$. Analyzes were performed with GraphPad Prism ${ }^{\circledR} 6.0$ software (GraphPad Software, La Jolla, CA,).

\section{Conclusions}

In conclusion, four benzo[a]phenoxazinium derivatives PS1-PS4 bearing different functional groups in the amino side chain and the first benzo[a]phenoxazinium dimer PS5 were prepared. The investigation on optical properties of PS1 to PS5 in water indicated that they are red light absorbers with low fluorescence quantum yields (0.025 0.116). The ROS production study revealed that all these benzo[a]phenoxaziniums produced ROS in an energy-dependent fashion, with PS4 having the highest ROS quantum yield. Finally, the anticancer PDT activities of this series of benzo[a]phenoxaziniums were evaluated for the first time. The bioassay results indicated that PS1 and PS4 show significant photodynamic activities against 4T1 cancer cells and NIH-3T3 normal murine fibroblast cells, and PS5 showed intriguing anticancer PDT activity selectively towards 4 T1 cancer cells over NIH-3T3 normal cells. Together with the optical properties and photodynamic bioassay results, this series of benzo[a]phenoxazinium derivatives can be highlighted as new PSs worthy of further investigation in anticancer PDT study.

Supplementary Materials: The following are available online at http:/ /www.mdpi.com/1420-3049/23/6/1436/ s1, ${ }^{1} \mathrm{H}-,{ }^{13} \mathrm{C}-\mathrm{NMR}, \mathrm{LR}-\mathrm{MS}$ and HR-MS spectra for PS1-PS5.

Author Contributions: Chemical synthesis and spectroscopic measurements, J.Z., J.-L.S. and Z.-Q.C.; ROS detection, W.T.d.S.J. and V.C.M.d.S.; Phototoxicity assay, M.C.R. and J.A.V.M.; Writing-Original Draft Preparation, J.Z.; Writing-Review, J.P.F.L., R.B.A. and H.Z.; Supervision, C.-S.J., L.A.M. and H.Z.; Project Administration, C.-S.J., H.Z.

Funding: This research was funded by [National Natural Science Foundation of China] grant number [21672082]; [Shandong Key Development Project] grant number [2016GSF201209]; [Young Taishan Scholars Program] grant number [tsqn20161037]; [Shandong Natural Science Foundation for Distinguished Young Scholars] grant number [JQ201721]; [Shandong Talents Team Cultivation Plan of University Preponderant Discipline] grant number [10027]; and the Brazilian Government Agencies FAP/DF [0193.001020/2015] and CNPq [447.628/2014-3].

Acknowledgments: Authors are greatful to Miss Jin-Tong Song for LC-MS and NMR analytical support.

Conflicts of Interest: The authors declare no conflict of interest.

\section{References}

1. Kennedy, J.C.; Pottier, R.H.; Pross, D.C. Photodynamic therapy with endogenous protoporphyrin. IX: Basic principles and present clinical experience. J. Photochem. Photobiol. B 1990, 6, 143-148. [CrossRef]

2. Zhang, J.; Jiang, C.S.; Figueiró Longo, J.P.; Azevedo, R.B.; Zhang, H.; Muehlmann, L.A. An updated overview on the development of new photosensitizers for anticancer photodynamic therapy. Acta Pharm. Sin. B 2018, 8, 137-146. [CrossRef] [PubMed] 
3. Dougherty, T.J.; Gomer, C.J.; Henderson, B.W.; Jori, G.; Kessel, D.; Korbelik, M.; Moan, J.; Peng, Q. Photodynamic therapy. J. Natl. Cancer Inst. 1998, 90, 889-905. [CrossRef] [PubMed]

4. Lim, S.H.; Thivierge, C.; Nowak-Sliwinska, P.; Han, J.; van den Bergh, H.; Wagnières, G.; Burgess, K.; Lee, H.B. In vitro and in vivo photocytotoxicity of boron dipyrromethene derivatives for photodynamic therapy. J. Med. Chem. 2010, 53, 2865-2874. [CrossRef] [PubMed]

5. Meng, Z.; Yu, B.; Han, G.; Liu, M.; Shan, B.; Dong, G.; Miao, Z.; Jia, N.; Tan, Z.; Li, B.; et al. Chlorin p6-Based Water-Soluble Amino Acid Derivatives as Potent Photosensitizers for Photodynamic Therapy. J. Med. Chem. 2016, 59, 4999-5010. [CrossRef] [PubMed]

6. Yano, S.; Hirohara, S.; Obata, M.; Hagiya, Y.; Ogura, S.; Ikeda, A.; Kataoka, H.; Tanaka, M.; Joh, T. Current states and future views in photodynamic therapy. J. Photochem. Photobiol. C 2011, 12, 46-67. [CrossRef]

7. Muehlmann, L.A.; Rodrigues, M.C.; Longo, J.P.; Garcia, M.P.; Py-Daniel, K.R.; Veloso, A.B.; de Souza, P.E.; da Silva, S.W.; Azevedo, R.B. Aluminium-phthalocyanine chloride nanoemulsions for anticancer photodynamic therapy: Development and in vitro activity against monolayers and spheroids of human mammary adenocarcinoma MCF-7 cells. J. Nanobiotechnol. 2015, 13, 36. [CrossRef] [PubMed]

8. Muehlmann, L.A.; Ma, B.C.; Longo, J.P.; Almeida Santos Mde, F.; Azevedo, R.B. Aluminum-phthalocyanine chloride associated to poly(methyl vinyl ether-co-maleic anhydride) nanoparticles as a new third-generation photosensitizer for anticancer photodynamic therapy. Int. J. Nanomed. 2014, 9, 1199-1213. [CrossRef] [PubMed]

9. Rodrigues, M.C.; Muehlmann, L.A.; Longo, J.P.; Silva, R.C.; Graebner, I.B.; Degterev, I.A.; Lucci, C.M.; Azevedo, R.B.; Garcia, M.P. Photodynamic Therapy Based on Arrabidaeachica (Crajiru) Extract Nanoemulsion: In vitro Activity against Monolayers and Spheroids of Human Mammary Adenocarcinoma MCF-7 Cells. J. Nanomed. Nanotechnol. 2015, 6, 1000286. [CrossRef]

10. Monge-Fuentes, V.; Muehlmann, L.A.; Longo, J.P.; Silva, J.R.; Fascineli, M.L.; de Souza, P.; Faria, F.; Degterev, I.A.; Rodriguez, A.; Carneiro, F.P.; et al. Photodynamic therapy mediated by acai oil (Euterpe oleracea Martius) in nanoemulsion: A potential treatment for melanoma. J. Photochem. Photobiol. B 2017, 166, 301-310. [CrossRef] [PubMed]

11. Yuan, L.; Lin, W.; Zheng, K.; He, L.; Huang, W. Far-red to near infrared analyte-responsive fluorescent probes based on organic fluorophore platforms for fluorescence imaging. Chem. Soc. Rev. 2013, 42, 622-661. [CrossRef] [PubMed]

12. Leitão, M.P.S.; Rama Raju, B.; Naik, S.; Coutinho, P.J.G.; João Sousa, M.; Gonçalves, M.T. Synthesis and photophysical studies of new benzo[a]phenoxazinium chlorides as potential antifungal agents. Tetrahedron Lett. 2016, 57, 3936-3941. [CrossRef]

13. Frade, V.H.J.; Goncalves, M.S.T.; Coutinho, P.J.G.; Moura, J.C.V.P. Synthesis and spectral properties of long-wavelength flurescent dyes. J. Photochem. Photobiol. A 2007, 185, 220-230. [CrossRef]

14. Frade, V.H.J.; Sousa, M.J.; Moura, J.C.V.P.; Gonçalves, M.S.T. Synthesis of naphtho[2,3-a]phenoxazinium chlorides: Structure-activity relationships of these heterocycles and benzo[ $a$ ]phenoxazinium chlorides as new antimicrobials. Bioorg. Med. Chem. 2008, 16, 3274-3282. [CrossRef] [PubMed]

15. Mizukawa, Y.; Ge, J.F.; Bakar, A.; Itoh, I.; Scheurer, C.; Wittlin, S.; Brun, R.; Matsuoka, H.; Ihara, M. Novel synthetic route for antimalarial benzo[a]phenoxazine derivative SSJ-183 and two active metabolites. Bioorg. Med. Chem. 2014, 22, 3749-3752. [CrossRef] [PubMed]

16. Lopes, M.; Alves, C.T.; Rama Raju, B.; Gonçalves, M.S.; Coutinho, P.J.; Henriques, M.; Belo, I. Application of benzo[a]phenoxazinium chlorides in antimicrobial photodynamic therapy of Candida albicans biofilms. J. Photochem. Photobiol. B 2014, 141, 93-99. [CrossRef] [PubMed]

17. Foley, J.W.; Song, X.; Demidova, T.N.; Jalil, F.; Hamblin, M.R. Synthesis and properties of benzo[a]phenoxaziniumchalcogen analogues as novel broad-spectrum antimicrobial photosensitizers. J. Med. Chem. 2006, 49, 5291-5299. [CrossRef] [PubMed]

18. Wainwright, M.; McLean, A. Rational design of phenothiazinium derivatives and photoantimicrobial drug discovery. Dyes Pigment. 2017, 136, 590-600. [CrossRef]

19. Cincotta, L.; Foley, J.W.; Cincotta, A.H. Novel red absorbing benzo[a]phenoxazinium and benzo[ $[a]$ phenothiazinium photosensitizers: In vitro evaluation. Photochem. Photobiol. 1987, 46, 751-758. [CrossRef] [PubMed]

20. Frade, V.H.; Gonçalves, M.S.; Moura, J.C. Synthesis and fluorescence properties of side-chain carboxylated 5,9-diaminobenzo[a]phenoxazinium salts. Tetradedron Lett. 2005, 46, 4949-4952. [CrossRef] 
21. Tang, Y.; Lee, D.; Wang, J.; Li, G.; Yu, J.; Lin, W.; Yoon, J. Development of fluorescent probes based on protection-deprotection of the key functional groups for biological imaging. Chem. Soc. Rev. 2015, 44, 5003-5015. [CrossRef] [PubMed]

22. Chen, S.; Zhao, X.; Chen, J.; Chen, J.; Kuznetsova, L.; Wong, S.S.; Ojima, I. Mechanism-based tumor-targeting drug delivery system. Validation of efficient vitamin receptor-mediated endocytosis and drug release. Bioconjug. Chem. 2010, 21, 979-987. [CrossRef] [PubMed]

23. Gülmez, A.D.; Göksel, M.; Durmuş, M.J. Silicon(IV) phthalocyanine-biotin conjugates: Synthesis, photophysicochemical properties and in vitro biological activity for photodynamic therapy. Porphyr. Phthalocyanines 2017, 21, 547-554. [CrossRef]

24. Li, K.; Qiu, L.; Liu, Q.; Lv, G.; Zhao, X.; Wang, S.; Lin, J. Conjugate of biotin with silicon(IV) phthalocyanine for tumor-targeting photodynamic therapy. J. Photochem. Photobiol. B 2017, 174, 243-250. [CrossRef] [PubMed]

25. Shervington, L.A.; Smith, N.; Norman, E.; Ward, T.; Phillips, R.; Shervington, A. To determine the cytotoxicity of chlorambucil and one of its nitro-derivatives, conjugated to prasterone and pregnenolone, towards eight human cancer cell-lines. Eur. J. Med. Chem. 2009, 44, 2944-2951. [CrossRef] [PubMed]

26. Song, J.L.; Zhang, J.; Liu, C.L.; Liu, C.; Zhu, K.K.; Yang, F.F.; Liu, X.G.; Figueiró Longo, J.P.; Alexandre Muehlmann, L.; Azevedo, R.B.; et al. Design and synthesis of pregnenolone/2-cyanoacryloyl conjugates with dual NF-kB inhibitory and anti-proliferative activities. Bioorg. Med. Chem. Lett. 2017, 27, 4682-4686. [CrossRef] [PubMed]

27. Mohareb, R.M.; El-Sayed, N.N.; Abdelaziz, M.A. The Knoevenagel reactions of pregnenolone with cyanomethylene reagents: Synthesis of thiophene, thieno[2,3-b]pyridine, thieno[3,2- $d]$ isoxazole derivatives of pregnenolone and their in vitro cytotoxicity towards tumor and normal cell lines. Steroids 2013, 78, 1209-1219. [CrossRef] [PubMed]

28. Szalóki, G.; Pantzou, A.; Prousis, K.C.; Mavrofrydi, O.; Papazafiri, P.; Calogeropoulou, T. Design and synthesis of 21-alkynylaryl pregnenolone derivatives and evaluation of their anticancer activity. Bioorg. Med. Chem. 2014, 22, 6980-6988. [CrossRef] [PubMed]

29. Takakusa, H.; Kikuchi, K.; Urano, Y.; Sakamoto, S.; Yamaguchi, K.; Nagano, T. Design and Synthesis of an Enzyme-Cleavable Sensor Molecule for Phosphodiesterase Activity Based on Fluorescence Resonance Energy Transfer. J. Am. Chem. Soc. 2002, 124, 1653-1657. [CrossRef] [PubMed]

30. Fan, J.; Dong, H.; Hu, M.; Wang, J.; Zhang, H.; Zhu, H.; Sun, W.; Peng, X. Fluorescence imaging lysosomal changes during cell division and apoptosis observed using Nile Blue based near-infrared emission. Chem. Commun. 2014, 50, 882-884. [CrossRef] [PubMed]

31. Garland, M.J.; Cassidy, C.M.; Woolfson, D.; Donnelly, R.F. Designing photosensitizers for photodynamic therapy: Strategies, challenges and promising developments. Future Med. Chem. 2009, 1, 667-691. [CrossRef] [PubMed]

32. Fernandez, J.M.; Bilgin, M.D.; Grossweiner, L.L. Singlet oxygen generation by photodynamic agents. J. Photochem. Photobiol. B 1997, 37, 131-140. [CrossRef]

33. Mosmann, T. Rapid colorimetric assay for cellular growth and survival: Application to proliferation and cytotoxicity assays. J. Immunol. Methods 1983, 65, 55. [CrossRef]

Sample Availability: Samples of the compounds PS1-PS5 are available from the authors. 